\title{
STAKEHOLDER INVOLVEMENT IN TEACHING AND LEARNING
}

\author{
Umaporn Supasitthimethee, Narongrit Waraporn, Kriengkrai Porkaew, Nipon Charoenkitkarn \\ School of Information Technology, King Mongkut's University of Technology Thonburi, Thailand
}

\{umaporn,narongrit,porkaew,nipon\} @ sit.kmutt.ac.th

\begin{abstract}
To connect with the students of the $21^{\text {st }}$ century, lecturers must understand their characteristics and know how to motivate them. Traditional approach, i.e., lecture-based approach, is usually not an effective approach in this century. At the School of Information Technology (SIT), we bring in stakeholders in education, such as alumni and professionals to help us in the teaching-learning process. It shows that stakeholder involvement in teaching and learning complements the traditional approach in education.
\end{abstract}

Keywords: Stakeholders in Education, Teaching-Learning Approaches, IT Education, IT Effective Learning

\section{INTRODUCTION}

In the recent decades, there have been many innovations and new emerging technologies, especially in the field of information technology. At the same time, students' behaviors have changed dramatically. SIT offers teaching programs in Information Technology, including B.Sc., M.Sc., and Ph.D. Since knowledge and skills in IT change rapidly, it may possibly be difficult for lecturers to always keep pace with new knowledge and gain new IT skills in order to educate students. By incorporating different stakeholders into the traditional teaching and learning undergraduate classes, it helps the school both in terms of educating the academic and teaching staff and the students. In this work, we focus only on the B.Sc. program. We have organized various activities and workshops that involve our alumni and external IT professionals so that the academic and teaching staff and students can both benefit from their experiences. Our activities are, for example, Programming and Network Bootcamps, Agile Software Development Workshop, Freshman-Junior Joint Project, and Alchemist Academic Practice Club. We found that integrating many teaching-learning approaches achieved a better result than using the traditional approach alone. Different approaches complement one another.

The following sections organize as follows. Section 2 mentions all stakeholders in education. Section 3 discusses various teaching-learning approaches. Section 4 shows some of the results and section 5 is the conclusion.

\section{BSC IT STAKEHOLDERS}

Modern higher education has adapted itself from policybased to stakeholder-based. For example [1] created an eLearning system for higher education requires stakeholders' analysis to define the need of all stakeholders. The Bachelor of Science in Information Technology, BSc IT, is a study program offered at School of Information Technology. The program currently has more than 400 students, 20 lecturers, and 10 staff. The program has produced IT professionals from our learning outcomes with the collaboration of stakeholders. The stakeholders can be divided into seven groups; Requirement Providers, Regulator, IT Academic Standard Maker, Policy Makers, Processors, Supporters, and Influencers as shown in Figure 1.

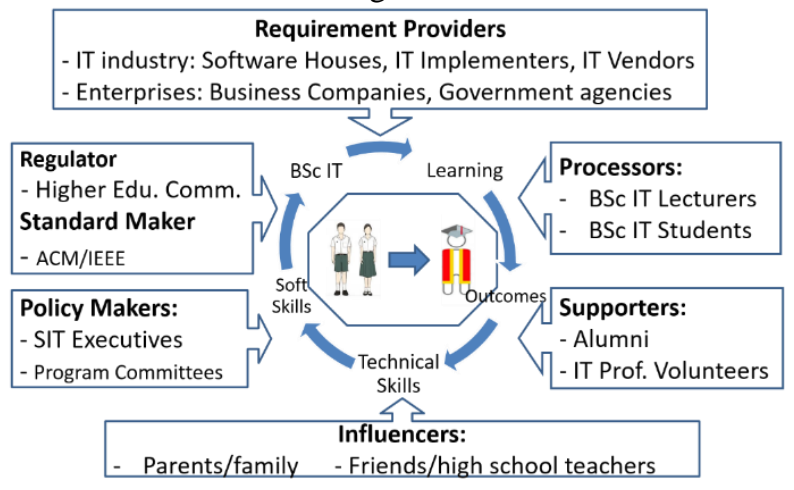

Fig. 1. Stakeholders of BSc IT program at SIT, KMUTT

\subsection{Requirement Providers}

In order to produce IT professionals for industry, we need to take into account the requirements of business organizations [2], [2]. For example, we have interviewed many software houses, IT implementers, and IT vendors, such as Thompson Reuters, a developer of financial software, CDG House and MFEC Co. Ltd., two of the largest software houses in Thailand, and IBM. We have also held discussions with IT-driven enterprises, such as Kasikorn Bank, Siam Commercial Bank, two of the leading commercial banks in Thailand, and Central Department Stores, the largest retailer in Thailand. These organizations have our alumni working for them. They are familiar with the output of the BSc IT program in both technical skills and soft skills. Therefore, they can give precise suggestions 
to us for the improvement of the program. Their improvement suggestions are used to determine the Program Learning Outcomes, PLO, of the program. However, [4] suggests that credentialing of stakeholders must be considered into a lever of systematic curricular transformation.

\subsection{Regulator}

Universities in Thailand are regulated by the Office of Higher Education Commission (OHEC) of Thailand. OHEC has defined the Thailand Qualification Framework, TQF, in order to improve the standards of higher education of Thai universities. One of the TQFs is TQF-Computer for computer study programs. It defined five major learning outcomes; ethics, knowledge, cognitive skills, interpersonal skills, and analytical and communication skills. The BSc IT program is one of the first programs to initiate the learning outcomes complying to the framework and approved by OHEC.

\subsection{IT Academic Standard Maker}

One of the major stakeholders that aims to encourage IT programs to raise educational levels to the global standard is the ACM/IEEE academic standard group. They provide the curriculum guidelines for many computer-related fields, including the IT curriculum guidelines for 2008 and the coming guidelines for 2017. We follow the body of knowledge guidelines in our BSc IT curriculum so that our students can be at the same level as other IT professionals who have graduated from the world class universities.

\subsection{Policy Makers}

The executive management team of SIT plays an important role in academic policies while the program committee closely advise and approve the activities of the program. For example, SIT has a policy, called "Do it right" for students, lecturers, and staff to experience a blend of theory and practices. The program committee must ensure that each practical course must equip students with experiences in enterprise-level software/hardware such as Oracle database and ERP, HP network equipment, IBM z/OS platform and AWS Amazon Cloud services. Consequently, our graduates will be proficient according to the requirements from the enterprises.

\subsection{Processors}

To achieve the effective PLOs of the program, students and professors are the most important stakeholders of our Generation Z students, who are familiar with the Internet and comfortable with technology, highly interact on social media. Providing them with academic resources over the
Internet, learning with technological tools and techniques, and communicating promptly over social media are the major adaptation for the lecturers. The successful foundation of the effective learning is the closeness between students and lecturer which is not only the technical skills they gain during practice or lab hours [5], but also the soft skills when they communicate with the lecturer.

SIT lecturers also need to gain IT experiences from real world businesses so that we can transfer knowledge and problem experiences effectively to our students. Hence, SIT set up a consultant unit called Electronic Services and Research Center, ESRC, to help government organizations and businesses to use IT to improve their business processes. In turn, our BSc IT lecturers can apply their IT knowledge and skills to solve business problems and also can learn new technologies [2] while helping them.

\subsection{Supporters}

Technologies always emerge in Information Technology in hardware, software, and techniques. The BSc IT program at SIT must expand these new experiences to students. One stakeholder that is heartily willing to share these experiences to the students is our alumni. They are working in the IT field with new technologies that are used in their organizations. Students in the program know each other even though they are in different years which is common in Thai universities. That is the main reason why they are willing to help the current students. The current students also prefer to have additional learning with someone who is of the same generation as them. Therefore, the BSc IT program must maintain a good relationship with alumni.

Another group of supporters has recently emerged now that social media has become common. They are professionals in the IT community. They have seen the problem of the slowing pace of academia when compared with the quickly emerging tools and techniques in IT. These problems reflect back to the IT community that lacks new staff equipped with these emerging technologies. They volunteer to help our students especially when the program is ready to adapt to the technology and the students show them their willingness. In return, the volunteers can increase their knowledge sharing skills so that their open innovation processes are improved [8].

\subsection{Influencers}

In a hierarchical society like Thailand, people have great respect for elders, especially, their parents. Most of the Thai students still live with their parents and receive financial support from them while studying at university. 
Therefore, support and some guidance from parents can, nonetheless, influence the study behavior of students. Also, former high school teachers also influence high school students on what to study. Hence, every year, SIT arranges an open house for high school teachers and students and parent orientation so that we can clarify our intention, learning outcomes and activities that will involve all students.

Last but not least, classmates and friends during their study are likely to be together for four years. Learning together, helping each other to understand the subjects, and working in group projects will give them an opportunity to improve soft skills of team management, leadership, and peer communication.

\section{TEACHING-LEARNING APPROACH}

This section discusses various teaching-learning approaches. Most approaches are initiated by faculty members, such as Programming and Network Bootcamps, and Freshman-Junior Joint Project. Agile Software Development Workshop is initiated by faculty members and volunteered by IT professionals. Alchemist Academic Practice Club is initiated by alumni and current students.

\subsection{Programming Boot Camp}

We regularly organize a Programming Bootcamp for our freshmen during the summer after they have taken programming classes in their first academic year. The purpose is to review their programming skills by bringing them to practice programming on a small but real problem. The students are divided into small teams, each of which has its own mentor. The alumni take part as mentors to assist the students. This Bootcamp helps the students prepare for their classes in the next academic year.

We enhance the programming experiences to freshmen during the summer through the Programming Boot Camp. Students stay overnight during the camp for four days with no extra cost to students. All students are required to join the camp as soon as after the semester is over.

Before the camp starts, we have a discussion with experienced IT professionals from software houses, IT vendors, and IT implementation companies about their expectation from young programmers. The discussion includes technologies, skills, attitudes, and issues new programmers. Their experiences, observations, and suggestions become our major planning guidelines for the programming boot camp.

At the beginning of the camp, we motivate students about the careers of programmers. We invite IT project managers and alumni to share experiences about the life of programmers and IT professionals. Students can then consider their career path. We also train students for additional skills needed for software development during the camp such as JSP and database programming. Freshmen do not usually learn these skills until they become sophomore. Architectural thinking on the software design has also been introduced to the students including the goals, the problem framework, the requirement specification contributed to the goals, and the sensitivity for different context [1].

Camp divides students into groups of three to four. Each group is composed of an A-student, a couple of average students and a weak student. The purpose is that they can help each other to learn how to work with people who have different skills. Each group will have SIT lecturers and alumni to encourage them to work on a challenging project and guide them to research to find a solution to their problems. We also gain help from the sophomores, juniors, and seniors who volunteer to help the freshmen to maintain positive attitudes about programming. The volunteers also help us in housing management and entertain the stressful campers during the camp. Group learning during the camp also helped students to know each other well. [6] shows that group learning and information sharing can improve the learning.

The camp improves not only the technical and soft skills, but also the perceptions of life. We invite a motivation team to give a talk about life. However, the effectiveness of the motivational talk does not come from the popularity of the speaker but from the closeness between the speaker and the students.

\subsection{Network and System Boot Camp}

A year after the programming boot camp, we implement a network and system boot camp focusing on problembased learning. The camp is mandatory for the SIT sophomores. In 2015, the camp was divided into five stations: Infrastructure Implementation, Network Monitoring, VoIP Configuration, Network Security, and Database Configuration. Each station has a series of problems for students to solve within one day. At each station, any group finishing all problems first will receive a prize on the following day.

To enable students to comprehend the problem, we give a clue after each hour has passed if the group cannot find a solution. We collaborated with juniors, seniors, researchers and volunteer alumni in order to help the students. Socialinteract among them with dashboard helped learning as group forum as also shown in [8]. Thus, at the end of each day, every group of each station was able to complete the problems.

However, there were suggestions about new technologies, the overlap of knowledge between camps and study, and the mandatory of the network system boot camp. Some students would like to join an internship or work abroad. In 2016, we adapted the camp by changing to three stations: Infrastructure Implementation, Network 
Monitoring, and Cloud Infrastructure-as-a-services. The camp became optional rather than mandatory. However, most students (eighty percent of the sophomores) still joined the new camp.

We received hardware support from our alumni. They donated several used blade servers for the BSc IT program to allow students to setup and configure the given servers. They also guided the juniors and seniors to set up the problems.

\subsection{Agile Software Development}

BSc. IT program regularly invites IT professionals to give a talk or a workshop for the academic staffs to update their knowledges and skills. Agile software development have been around for quite a while in the industry. Although the academic staffs are familiar with this methodology of software development, they do not have first-hand experience in doing it. Inviting experts in the industry to give a workshop is a shortcut for the academic staffs to learn and experience new things. Rather than just having a workshop for the academic staffs, the experts offered to give a three-day long workshop for the students. The Agile software development experts also recruited 30 professional volunteers to help train the junior students. The junior students are the target of this project because they are about to start their capstone projects which are suitable for exploiting the Agile software development methodology. From the students' feedback, they gained valuable knowledge and skills from different perspectives than what they usually gain from the normal teaching and learning classes. In addition, they felt more relaxed and were willing to take part in this activity.

\subsection{Freshman-Junior Joint Project}

On this project, the practical part of the freshmen programming course is integrated with that of the junior software project management course so that the freshmen teams can work with the junior teams on small software projects. The former will practice programming based on the project designed by the latter. The former does not possess any knowledge to design a program whereas the latter does not have to spend time on programming. However, they must make sure that the programs that they have designed are usable. They learn how to manage their projects that consists of freshmen as their project members. They also give advices to freshmen on programming. Junior students learn in many ways: (1) learning (how to program) by teaching (freshmen) and (2) learning by doing (i.e., managing projects).

\subsection{Alchemist}

An academic practice club, named Alchemist, has been established at SIT. This club consists of alumni volunteers and students from different years who would like to gain hands-on experience. Their voluntary activities involve helping the university to develop small computer programs for use in various events organized by the university, e.g. the KMUTT Open House. This project is initiated by the students and alumni themselves and they seek supports from the school. Some of the supports are in the form of financial support. Some are in the form of equipment. Some are the problem for them to work on. Currently, there are 34 students and 6 alumni joined the club. There are about 10 students from each class (i.e., freshmen, sophomore, and junior, but there is no senior). The demand from the students who wanted to join the club were quite high but the founded members could not open for new members because the older generations much take care of the younger generations. They do not have enough older generations to take care of the younger ones. The number of members will gradually increase in the years to come.

\section{RESULTS}

This section shows some of the results of the projects. We conducted a survey of freshmen who participated in the programming boot camps for the last three years. The average results of the Likert scale survey between 2014 and 2016 are shown in Table 1.

The result of the survey shows that the camps were beneficial to the camp participants. They would like the BSc IT program to organize the camp again for the following year to come. As for the stakeholders, the sophomore and junior students who volunteered to support camp activities for freshmen could help inspire and motivate freshmen to be interested in software development. However, the guest speakers who are IT professionals could share experiences with the freshmen well but not as effectively as the sophomore and junior students. This due to the sophomore and junior students were closer to the freshmen than the invited IT professional speakers. The sophomore and junior students also spent more time in the camp than the speakers.

However, the objective of the camp was to inspire the freshmen about careers in software development but not to substantially increase their skills and knowledge within a few days. Even though, their software development skills and interest in software development increased after the camp, the knowledge gained from the training was not very high. 
Table 1: Survey of Programming Boot Camps between 2014 and 2016.

\begin{tabular}{|l|l|l|l|}
\hline & $\mathbf{2 0 1 4}$ & $\mathbf{2 0 1 5}$ & $\mathbf{2 0 1 6}$ \\
\hline $\begin{array}{l}\text { Software Development Skills } \\
\text { before the camp }\end{array}$ & 2.43 & 2.58 & 2.65 \\
\hline $\begin{array}{l}\text { Software Development Skills after } \\
\text { the camp }\end{array}$ & 3.27 & 3.70 & 3.49 \\
\hline $\begin{array}{l}\text { Level of Interest in software } \\
\text { development before the camp }\end{array}$ & 2.82 & 3.03 & 3.75 \\
\hline $\begin{array}{l}\text { Level of Interest in software } \\
\text { development after the camp }\end{array}$ & 3.55 & 3.87 & 4.02 \\
\hline $\begin{array}{l}\text { Knowledge gained from the } \\
\text { training }\end{array}$ & 3.47 & 4.17 & 3.67 \\
\hline Camp was beneficial. & 3.62 & 4.21 & 4.42 \\
\hline $\begin{array}{l}\text { Camp motivates you to learn in } \\
\text { years to come. }\end{array}$ & 3.64 & 4.01 & 4.21 \\
\hline $\begin{array}{l}\text { Camp should be organized again } \\
\text { next year. }\end{array}$ & 3.59 & 4.28 & 4.62 \\
\hline $\begin{array}{l}\text { Sophomore/junior/senior inspire } \\
\text { and motivate you in software } \\
\text { development. }\end{array}$ & 4.02 & 4.44 & 4.57 \\
\hline $\begin{array}{l}\text { Overall knowledge received from } \\
\text { guest speaker }\end{array}$ & 3.88 & 3.82 & 3.87 \\
\hline
\end{tabular}

For other projects, they were still in their infancy. However, they showed promising results. The students who participated in the projects gave similar feedbacks. They enjoyed the projects and gained knowledge and experiences. They would like the projects to organize again in the years to come.

\section{CONCLUSION}

The BSc IT program at the School of Information Technology deployed different learning approaches by bringing in various stakeholders in education to help train students in addition to the traditional lecture-based approach. Common characteristics among various projects were (1) active learning, (2) problem-based learning, and (3) the closeness between students and the stakeholders involved in the projects. Students also paid more attention to the learning in small groups than in large groups. The trainers could also give more attention to the students in small groups as well. New teaching-learning approaches can also draw attention from the $21^{\text {st }}$ century students, who get bored easily.

\section{References}

[1] Nicole Wagner, Khaled Hassanein and Milena Head, "ELearning in Higher Education: A Stakeholders' Analysis," in Proc. $28^{\text {th }}$ Inter. Conf. on Information Technology
Interfaces, (Cavtat, Dubrovnik, Croatia; 19-22 June 2006), 6 pp., 2006.

[2] Jailani Md Yunos, Lai Chee Sern, and Nor Hidayah Hamdan, "Changes and Challenges in Sustainability of Technical and Vocational Education and Training - Teacher Education Programme: A Case Study," in Proc. IEEE $8^{\text {th }}$ Inter. Conf. on Engineering Education, ICEED2016, (Kuala Lumpur, Malaysia; 7-8 Dec. 2016), 6 pp., 2016

[3] Constanta Nicole Bodea, Radu Ioan Mogos, Maria-Iuliana Dascalu, Alin Dragos Bogdan Moldoveanu, George Dragoi, Martina Huemann, and Matthijs Schilder, "Emerging Technologies: Adding Dimensions to Lifelong Learning," in Proc. Zooming Innovation in Consumer Electronics Inter. Conf., ZINC2016, (Novi Sad, Serbia; 1-2 June 2016), 4 pp., 2016

[4] Jennifer Karlin, Rebecca Bates, Cheryl Allendoerfer, Dan Ewert, and Ron Ulseth, "Credentialing in the CSET Education Change Process," in Proc. IEEE Frontiers in Education Conference, FIE2016, (Erie, PA, USA; 12-15 Oct. 2016), 5 pp., 2016.

[5] Lin Zhao, and Karinna Vernaza, "Teaching first year engineering students engineering design process and problem solving through service learning projects," in Proc. IEEE Frontiers in Education Conference, FIE2016, (Erie, PA, USA; 12-15 Oct. 2016), 7 pp., 2016.

[6] M. Vranic, D. Pintar, L. Humski, Z. Skocir,F. SkopljanacMacina, I. Brstilo, N. Duho, K. Klasnic, S. Malisa, and A.M. Zukovic, "University Social Network Benefits Analysis and Proposed Framework," in Proc. 24 ${ }^{\text {th }}$ Inter. Conf. on Software, Telecommunications and Computer Networks, SoftCOM2016, (Split, Croatia; 22-24 Sept. 2016), 5pp., 2016

[7] Preethu Rose Anish, "Towards an Approach to Stimulate Architectural Thinking during Requirements Engineering Phase," in Proc. IEEE $24^{\text {th }}$ Inter. Requirements Engineering Conf., RE2016, (Beijing, China; 12-16 Sept. 2016), 6 pp., 2016

[8] Beat A. Schwendimann, Marı Jesus Rodriguez-Triana, Andrii Vozniuk, Luis P. Prieto, Mina Shirvani Boroujeni, Adrian Holzer, Denis Gillet, and Pierre Dillenbourg "Perceiving Learning at a Glance: A Systematic Literature Review of Learning Dashboard Research," IEEE Transactions on Learning Technologies, vol. 10, issue 1, pp. 30-41, 2017. 